\title{
LA PALABRA AUSENTE. REFLEXIONES AL MARGEN DE UN ENSAYO PERDIDO DE ALEJO CARPENTIER
}

\author{
Bernat Garí Barceló \\ Universitat de Barcelona \\ Barcelona, España \\ bernatgari@ub.edu
}

RESUMEN / ABSTRACT

El presente estudio pone de manifiesto que existen filiaciones entre la producción narrativa de Alejo Carpentier y su ensayística musicológica. El ensayo musicológico de Carpentier antecede el conjunto de su producción más destacada y desempeña una labor exegética que alumbra técnicas, recursos narratológicos y rasgos escriturarios de la novelística autoral. Con mi investigación ilustraré el desarrollo teórico de dicho modelo y sus filiaciones, cuyo valor sistemático el autor puso de relieve en un ensayo ignoto: Tristán e Isolda en Tierra Firme (1949). Análogamente, rastrearé funcionalmente su realización estética en tanto poética generacional que determinó las derivas de algunas de las figuras centrales del 'boom'.

Palabras ClaVe: Carpentier, Wagner, ensayo musicológico, romanticismo, novela regionalista.

\section{THE MISSING WORD. REFLECTIONS ON A LOST ESSAY BY ALEJO CARPENTIER}

The study highlights the associations present in Alejo Carpentier's fiction and his musicological essays. His musicological essays precede the body of his most important works and they underline techniques, narrative resources and writing characteristics, which contributed to his fiction production. The systematic value of this model was expounded by the author in an unknown essay called Tristán e Isolda en Tierra Firme (1949). In this research work, I will illustrate the theoretical development of this model, its filiations and its aesthetic realisation as a generational poetic, which determined the work of some central writers of the Latin American Boom.

KEYWORDS: Carpentier, Wagner, musicological essay, romanticism, regionalist novel. 
El hombre hallado dentro y no fuera, lo universal en lo local, lo eterno en lo circunscrito. Ese sistema, ese método de acercamiento, único posible en América, es de pura cepa romántica, puesto que tiende a fomentar un necesario nacionalismo prólogo de un más amplio y más profundo conocimiento de la realidad circundante. El nacionalismo, bajo cualquiera de sus formas, es una noción que debemos al romanticismo.

Alejo Carpentier

¿Dónde encontraría el filósofo un guía mejor iniciado para el laberinto del alma moderna, un creador de almas más elocuente que Wagner? Por boca de Wagner habla la modernidad su lenguaje más íntimo: no oculta su bien ni su mal, ha perdido todo pudor ante sí misma... Wagner resume la modernidad. No hay remedio, hay que comenzar por ser wagneriano.

Friedrich Nietzsche

\section{LA PALABRA OBVIADA}

El 12 de setiembre de 1927, Carpentier dirige una carta a Manuel Aznar a raíz de la polémica suscitada por el artículo de Guillermo de la Torre "El meridiano intelectual de América" publicado en La Gaceta Literaria en abril del mismo año. En dicho artículo, Guillermo de la Torre exhortaba a los escritores peninsulares a devolver la centralidad cultural del hispanismo a Madrid tras el éxito colosal del programa modernista y vanguardista que, a ojos vista, supuso un giro copernicano en lo que a la recepción editorial de la literatura escrita en español se refiere. América Latina, por primera vez, se ponía a la vanguardia y hacía efectiva, gracias a la labor ingente de autores como Darío, Martí, Nájera o Rodó, y, más tarde, Neruda o Huidobro, su independencia cultural de la vieja metrópolis.

Madrid, según Guillermo de la Torre, debía ser, ultrajada la hombría española por los méritos de allende los mares, el meridiano intelectual de la cultura hispánica en aras de exorcizar a los jóvenes vanguardistas de las derivas afrancesadas e italianizantes que "amenazaban" su escritura. El artículo sin duda molestó, generó lato sensu una disputa entre apocalípticos e integrados -si readaptamos para la ocasión la nomenclatura propagada por Umberto Eco--, puso en guardia la vieja escolta ante la pujanza adquirida por el programa literario de los jóvenes latinoamericanos, y desató, del otro lado, 
reacciones de todo fuste y pelaje. La más vistosa, firmada bajo el estupendo pseudónimo de Ortelli y Gasset (atribuida a Borges y Carlos Mastronardi), llevaba un título que lo dice todo: "Un meridiano encontrao [sic] en una fiambrería". La respuesta de Carpentier, más comedida, tampoco se hizo esperar y, como decía, fue publicada en formato epistolar en el Diario de la Marina en setiembre del citado año.

Carpentier, en dicha carta, postula que los escritores de La Gaceta Literaria son "los parientes que se quedaron en casa" (Carpentier, La novela latinoamericana 228) y que para el continente no hay meridiano que valga, sino el que América pueda hallar dentro de sí: en su raza, su historia, sus músicas, costumbres, danzas y en un lenguaje cifrado que espejee "la presencia fáustica del indio y del negro" (Carpentier, El reino 14), su ontología; como señalará el autor, años más tarde, en el prólogo a El reino de este mundo. El escritor latinoamericano ha de hallarse dentro y no fuera, en lo propio y no en lo genérico, en lo genético y no en lo ecuménico,

y no porque una fobia egocentrista se haya apoderado de nuestras más lozanas mentalidades sino porque los problemas ideológicos que se plantean a sí mismas son peculiarísimos, y difieren totalmente de los que pueden inquietar a los escritores del Viejo Continente (Carpentier, La novela latinoamericana 227).

El texto de Carpentier, poco conocido, interesa menos por lo polémico (o por sus planteos ante un debate, al día de hoy, extenuado y prácticamente olvidado) que por su contenido conceptual, pues constituye el anclaje desde el que el autor problematiza y conceptualiza algunas de las líneas vertebradoras de su programa narrativo, cristalizado, años después, en dos textos raros; raros por desatendidos, pese a su centralidad en el itinerario productivo del autor: el tratado La música en Cuba (1946), por un lado, y Tristán e Isolda en Tierra Firme (1949), por el otro.

La herencia de Carpentier es tan indeleble para los autores que vendrán que vale la pena detenerse a rastrear su programa estético desde estos escritos $\mathrm{y}$, particularmente, desde Tristán e Isolda en Tierra Firme, que, lo veremos en breve, permite una lectura en tanto manifiesto generacional ${ }^{1}$. Se ha hablado

En este escrito me centraré, principalmente, en restablecer genéticamente la estética carpenteriana desde un texto medular a todos los efectos, Tristán e Isolda en Tierra Firme, que contiene las claves de lectura de la narrativa autoral. Su otro ensayo, La música en Cuba, 
mucho del Carpentier novelista, del Carpentier cuentista, del Carpentier ensayista e, inclusive, del Carpentier musicólogo, pero, me interesa, sobre todo, insistir en esa otra faceta del autor rara vez señalada: la del Carpentier lector. Tristán e Isolda en Tierra Firme alumbra, en ese sentido, la biblioteca del autor, su exégesis de la tradición canónica en la que se incardina y su apropiacionismo caníbal con estímulos de distinta procedencia.

Tristán e Isolda en Tierra Firme opera como una poética en la que Carpentier crea a sus precursores - que diría Bloom-y funda e institucionaliza un nuevo modo de pensar América. La América resemantizada de Carpentier cifra la entrada de América Latina en la modernidad y fuerza el tránsito de la América como tema a la América como problema, pues si, como aduce el autor, el regionalismo literario había extenuado sus recursos procedimentales y había crispado hasta el límite sus potencialidades estéticas en un intento de producir un lenguaje literario propio que, evidentemente, tomaba lo americano como leitmotiv, la América que ahora interesa deberá renovarse y buscar otra tradición que dramatice su identidad y recodifique su lenguaje. Esa tradición, ya lo adelanto, es el romanticismo alemán.

En definitiva, la cuestión nuclear que vertebra Tristán e Isolda en Tierra Firme podría sintetizarse del siguiente modo: ¿de qué manera la recepción tardía de determinados postulados del romanticismo alemán puede reconfigurar los usos escriturarios del escritor latinoamericano contemporáneo?

\section{LA PALABRA PERDIDA}

El escrito Tristán e Isolda en Tierra Firme es publicado, por primera vez, el 4 de setiembre de 1949 en la revista venezolana Cultura Universitaria del periódico El Nacional, y, a lo largo de los próximos meses, en la editorial Imprenta Nacional de Caracas, en una edición única, oportunamente acompañada de un sucinto subtitulo aclaratorio, que cifra el procedimiento desplegado por el autor a lo largo del escrito y que reza así: "reflexiones al margen de

es indisociable del primero, como señalaré debidamente, pero no detallaré sus implicaciones, pues el espacio me lo impide. A tales efectos, pueden consultarse los artículos de Bernat Garí "Sobre un novísimo concepto: la microcosmía sinfónica. Pesquisas identitarias desde el ensayismo musicológico de Carpentier", o, en su tesis, La ensayística musicológica de Alejo Carpentier. Eufónica vía a una poética de la novela, en el capítulo que corresponda. 
una representación wagneriana". El dispositivo paratextual parece sugerir que unas reflexiones de otra índole, estratégicamente licuadas, quedarán al margen de la representación wagneriana, $y$, sin embargo, colman en la práctica la totalidad del texto. En realidad, el movimiento es doble, pues, por un lado, el anclaje y firmamento de esas "reflexiones al margen", su materia prima, será la interpretación de lo wagneriano como síntesis y culminación del romanticismo alemán; y, por el otro, la fijación del wagnerianismo como fenómeno social (como epifenómeno), que aparece desplegado a duras penas a lo largo de las dos o tres páginas iniciales, es lo que exacerba la escritura del ensayo y su resolución. En fin, Tristán e Isolda de Wagner queda, contra todo pronóstico, al margen de unas reflexiones cuyo núcleo protagónico será el programa estético del propio Wagner, debidamente reformulado por Carpentier, en un juego de espejos y contraespejos que involucran lo wagneriano en el centro del texto y su periferia, y que cimientan sumariamente la poética carpenteriana.

Dicho ensayo, que es “contemporáneo del ensayo-prólogo a El reino de este mundo y reverso de la misma moneda respecto de este" (Baujin 85), cortocircuita el programa narrativo del primer Carpentier, incardinado por aquel entonces en la tendencia folclorizante del Grupo Minorista, y modifica sus estrategias recursivas y escriturales. El cambio es evidente, sobre todo, desde la novela El reino de este mundo (1949) en adelante, si bien el cuento "Viaje a la semilla", publicado en el año 1944, prefigura el redireccionamiento de la prosa autoral.

Si citaba, al principio de este escrito, la carta del autor a Manuel Aznar era porque constituye un enclave óptimo desde el que rastrear las filiaciones estéticas del primer Carpentier. Vemos, por ejemplo, en un fragmento aislado de la carta, que para el autor "desde el río Grande hasta el Estrecho de Magallanes, es muy difícil que un artista joven piense seriamente en hacer arte puro o arte deshumanizado. El deseo de crear un arte autóctono sojuzga todas las voluntades" (Carpentier, La novela latinoamericana 227; énfasis mío). El propósito de cifrar lo americano es indisociable del bosquejo del folclore y del sustrato telúrico y ancestral de unos pueblos emplazados en los cauces mismos de la transculturación, que el autor resuelve en un trabajo de campo materializado en una narrativa costumbrista de corte experimental. El tratamiento al detalle de la especificidad antropológica y cultural del mestizo se torna así un imperativo estético a todos los efectos. Y sabemos que la primera y única realización narrativa de dicho periodo es la novela Écue-Yamba-Ó que, justamente, Carpentier se ocupará de desautorizar a lo largo de su vida 
hasta permitir su reimpresión a finales de los años sesenta tras haberse puesto en circulación una edición pirata del texto atestada de errores ortográficos que, a ojos vista, fustigaron el imperturbable sueño del escritor. Esa primera novela, según Carpentier, es "un intento fallido por el abuso de metáforas, de símiles mecánicos, de imágenes de un aborrecible gusto futurista y por esa falsa concepción de lo nacional que teníamos entonces" (Leante 22). En definitiva, un artefacto trunco, una bagatela o meras "escalas y arpegios de estudiantes" (Carpentier, Écue 26), que certifican los planteos estéticos del joven Carpentier y su ulterior deriva.

La misiva a Aznar es también el espacio privilegiado de unas reflexiones, registradas a vuelapluma, cuya realización extrema toma forma en el ensayo wagneriano. Me refiero a la premisa carpenteriana según la cual la articulación de un arte autóctono y vital se asocia a un "gran fondo de ideales románticos". La especificidad histórica de una América emancipada, como quien dice, hace dos días, su singularidad paisajística y topográfica, su ubicación geopolítica o el sustrato antropológico del mestizo son coyunturas que, en opinión del autor, "propician ciertos ideales románticos" (Carpentier, La novela latinoamericana 227). Estas ideas, apenas esbozadas, presagian el núcleo programático de Tristán e Isolda en Tierra Firme en donde lo popular y lo folclórico, asumidos aún como materia prima novelizable, adquieren nuevo rango y consideración.

Carpentier despliega, en Tristán e Isolda en Tierra Firme, una escritura que intertextualiza en distintas direcciones. Primero, con el firme e inaplazable propósito de matar al padre y leer desde un espacio crítico las tendencias que anteceden la articulación del ensayo. El parricidio es ineludible, y precede siempre la articulación de una renovación total, abonada necesariamente sobre el fermento de los muertos. Segundo, en el ensayo, Carpentier crea a sus precursores, redirecciona su organigrama de lecturas y principia el rebrote de un regionalismo literario reconstituido y cristalizado en un nuevo ciclo creador que rebase, sin omitirla, la corriente descriptivista de principios de siglo para elevarla de lo local a lo universal, de lo contingente a lo perpetuo. Para hacerlo aún más explícito, en el ensayo, Carpentier cita a Unamuno: "Es dentro y no fuera, donde hemos de hallar el hombre; en las entrañas de lo local y circunscrito [sic] lo universal, y en las entrañas de lo temporal y pasajero, lo eterno" (Carpentier, Tristán 17). Los principios narrativos del regionalismo se revelaron prontamente insuficientes para el autor y propiciaron, si lo vemos retrospectivamente, un via ascensis análogo al del movimiento romántico: "el nacionalismo ascendente [apunta Claudio Guillén] es lo que 
cimentará un internacionalismo nuevo" (42). Retengamos dichas ideas, pues condensan la naturaleza del ensayo en cuestión.

En Tristán e Isolda en Tierra Firme, Carpentier postula una poética reactiva que se resuelve en la refutación de las corrientes automatizadas de la vanguardia europea, en la obstrucción de determinadas derivas afrancesadas formalmente cifradas en el modernismo finisecular, y en una reconfiguración material y epistemológica de la novela regionalista. De este modo, cuando Carpentier señala que "sobreestimábamos grandemente el espíritu innovador que en aquellos días se manifestaba en Europa" (Carpentier, Tristán 11), lo hace en miras de desautomatizar los usos fosilizados de la vanguardia europea. El prólogo a El reino de este mundo que espejea, según varios indicios, el ensayo wagneriano también previene contra esa automatización recursiva: "pobreza imaginativa, decía Unamuno, es aprenderse códigos de memoria. Y hoy existen códigos de lo fantástico, basados en el principio del burro devorado por un higo, propuesto por los Cantos de Maldoror como suprema inversión de la realidad" (Carpentier, El reino 8-9). Asimismo, cuando el autor formula que "Unamuno, desde una España que habíamos olvidado demasiado a favor de París [...] se cansaba de ponernos en guardia contra el cosmopolitismo, enemigo de la verdadera universalidad" (Carpentier, Tristán 14), o, cuando más adelante previene a sus coetáneos de un influjo accidental, al dictado de las modas, sus invectivas se dirigen al lugar común del modernismo y los "cisnéfilos". Lo indica el autor explícitamente cuando se refiere a la "moneda feble, de curso forzoso, debida a la introducción caprichosa, innecesaria, de una tendencia artística o literaria de Europa. Ejemplo típico: el Modernismo poético, que produjo verdaderos monstruos al querer trasplantar en nuestro suelo los mejores arbustos del Parnaso, del Simbolismo" (Carpentier, Tristán 35; énfasis del autor). Lo que no han descubierto los autores latinoamericanos, según Carpentier, es que "París pide a cada cual que sea lo que es" (Carpentier, Tristán 16) y que el meridiano intelectual de América, como se puso de manifiesto en la carta a Aznar, debe buscarse en el sitio adecuado, esto es: adentro. No obstante, ese adentro ya no puede ser el del regionalismo literario $-\mathrm{y}$, en ese punto, difiere de sus postulados en la mentada carta-:

Si el localismo fue, hasta ahora, un necesario tránsito hacia una búsqueda de lo universal en las entrañas de lo local, debemos rebasar muy pronto la etapa del "nacionalismo entre fronteras" [...] América habrá hallado su verdadera voz, cuando haya establecido verdaderas 
síntesis de sus herencias culturales y tenga una conciencia de la universalidad de sus mitos (Carpentier, Tristán 41).

El movimiento que sigue es previsible, pues un autor como Carpentier no se arriesgaría a dar un salto al vacío. La negatividad carpenteriana, su pulsión edípica, se traduce en creación, pues pulverizada la operatividad del modernismo, la vanguardia y el regionalismo en tanto estrategias discursivas y nomenclatura, Carpentier reivindica el romanticismo como enclave natural, como hábitat, desde el que refundar su lenguaje literario. Las alusiones de este giro a lo largo de Tristán e Isolda en Tierra Firme no se hacen esperar y, muerto el padre, se regresa al hogar del abuelo en un itinerario cifrado en el ascenso de lo local a lo universal: "ese sistema, ese método de acercamiento, único posible en América, es de pura cepa romántica, puesto que tiende a fomentar un necesario nacionalismo, prólogo de un más amplio y más profundo conocimiento de la realidad circundante" (Carpentier, Tristán 17).

Uno de los autores mentados en el ensayo, que modelan la poética carpenteriana y la tradición filosófica en la que se inscribe, es Johann Gottfried Herder, instigador de la nueva conciencia concebida en el entorno pietista de los pueblos germánicos del XVIII. La ontología herderiana desgrana una serie de nociones que serán cenitales en la vertebración de la conciencia romántica: su dinamización de la historia, concebida en términos estrictamente teleológicos; la fijación de una sensibilidad personalista constitutiva del entramado comunitario o la preponderancia que el terruño adquiere en la configuración de la identidad de los pueblos son, entre otros aportes, algunas de dichas ideas. La figura de Herder, mediatizada por la intervención programática de Carpentier, interesa por su reevaluación del folclore y el acervo popular como materia prima a codificar literariamente. Aparte, el patriotismo herderiano prefigura la articulación de un mapamundi intercultural en sintonía con la Weltliteratur acuñada por Goethe decenios después: "no hay ningún pueblo [señala Herder] que sea el pueblo escogido por Dios en exclusiva; todos han de buscar la verdad, el jardín de la mejor comunidad ha de ser cultivado por todos [...] Ningún pueblo de Europa puede cerrarse frente a los otros y decir neciamente: en mí y solo en mí mora toda la sabiduría" (cit. en Safranski 28).

Dicha noción es importante pues, en tanto dispositivo heredado, autoimpuesto, confronta al novelista hispanoamericano con la problemática del terruño y el folclore, y delimita el nuevo espacio de acción desde el que renovar la gramática regionalista y sus códigos: "describiéndose los paisajes, 
nombrándose a [sic] los árboles, haciendo aspirar el perfume de sus hojas, es como se logra alzar lo nacional hacia lo universal" (Carpentier, Tristán 23). El asunto adquiere tintes poco menos que teológicos: la labor del poeta pasa, según Carpentier, por un alumbramiento de lo innominado, en la línea del Adán de William Blake o el yo lírico de Hölderlin. En fin, en la asignación del nombre se pone en juego el desocultamiento de la cosa significada. Este es el principio medular, postulado en términos de superación, que condiciona el ciclo novelístico del autor desde 1949 en adelante y que, como gesto, supone un reingreso en la noción goethiana de Weltliteratur.

El sistema carpenteriano valida un ecumenismo estético de raigambre romántica que confiere un valor inaudito al componente representacional de la palabra, en tanto que esta, debidamente tratada, se convierte en el instrumento óptimo de esencialización de la realidad. La palabra debe recontextualizarse, humanizarse, liberarse de la sonoridad exótica y alucinatoria que adquiere en la novela de la tierra, y ultimar la consolidación de un lenguaje en vías de fijación. De ahí que para Carpentier el barroco sea la condición de posibilidad de una lengua viva que rebase por los bordes, expandidos sus horizontes semánticos, los lindes cognitivos que el español peninsular impone a sus coetáneos del continente. El autor señala, en la conferencia "Lo barroco y lo real maravilloso" (1975), que el barroco es el sustrato epistemológico de América en tanto que "toda simbiosis, todo mestizaje, engendra un barroquismo. El barroquismo americano se acrece con la criollidad, con el sentido del criollo, con la conciencia que cobra el hombre americano, [...] la conciencia de ser otra cosa" (Carpentier, Razón 54). Es por ello que en Tristán e Isolda en Tierra Firme, Carpentier pone en cuarentena cualquier postulado (neo)clasicista, definitorio de algunos avatares musicales del momento, pues ninguna forma de clasicismo bienintencionado, en detrimento de lo barroco, es consustancial a América: "tanto fue el cántaro neoclásico a la fuente que se hizo, al fin, pavimento del infierno" (31).

El apropiacionismo del fermento romántico y sus hallazgos estéticos también toma forma en la inusitada virulencia con la que Carpentier arremete contra el ensayismo de Ortega y Gasset. Hoy, un siglo más tarde, leídos a la luz de un ambiente menos revuelto por el experimentalismo y asumidos los hallazgos del vanguardismo como coqueta provocación performativa o mobiliario doméstico accesible en época de rebajas, algunos textos orteguianos generan, en el mejor de los casos, cierto sonrojo. En La deshumanización del arte, Ortega postula una refrigeración de la mirada que le lleva a decir que "el melodrama llega en Wagner a la más desmesurada exaltación [...] 
Ya en Wagner la voz humana deja de ser protagonista y se sumerge en el griterío cósmico de los demás instrumentos" (33-34), o que "de Beethoven a Wagner toda la música es melodrama" (31). Quien se haya extasiado con la sonata beethoveniana o con su fáustico cuarteto de cuerda, con las rapsodias húngaras de Liszt o con el Tristán de Wagner, no puede menos que cerrar el libro y tirarlo por la ventana. Al menos eso hizo Carpentier cuando señala que "Ortega y Gasset, tan inteligente, tan lúcido, tan seductor, nos resultó, en aquellos días, uno de los peores truchimanes de la modernidad, por vía de un malhadado artículo, titulado Musicalia" (Carpentier, Tristán 12; énfasis del autor). Y añade, a tenor de las intervenciones de Ortega en La Gaceta Literaria en materia musicológica:

Decir que "la música de Debussy pertenece al linaje de cosas irremediablemente impopulares" es un error; pero decir que la música romántica es "exactamente la expresión del lugar común sentimental, halago al pacífico comerciante, al empleado de Municipio, al virtuoso profesor y a todas las señoritas de comptoir", es monstruoso (12; énfasis del autor).

Una apreciación más al respecto. Carpentier no refuta sin solución de continuidad los aportes del arte nuevo. Para él, La consagración de la primavera de Stravinsky, la poética musical de Heitor Villa-Lobos o la obra pictórica de Wifredo Lam se reapropian de los hallazgos vertebradores del vanguardismo, pero siguen afiliados a un fondo vivo de ideas de pura cepa romántica. El atonalismo de la consagración stravinskiana responde, por ejemplo, a una voluntad de regeneración formal y estructural del dispositivo sinfónico, que poco o nada debe al gusto por la provocación: la experimentación está al servicio de otras ideas -como medio y no como fin en sí misma-, a saber, el reciclaje y rehabilitación del acervo folclórico y la articulación de nuevas modalidades acentuales, entre otras cosas. Dichos usos, según Carpentier, "no eran sino herencia y retoños del romanticismo, cuando no por el espíritu, por la técnica"2 (Carpentier, Tristán 14). Lo mismo ocurre con la pintura de Wifredo Lam, cuyo emplazamiento, en obras como La jungla o Maternidad

\footnotetext{
También en La música en Cuba se señala que los recursos sincopados y el desplazamiento acentual en La Consagración de la Primavera articulan una poética novedosa reciclable para América Latina: "Los que ya conocían la partitura de La consagración de la primavera [de Stravinsky] -gran bandera revolucionaria de entonces-, comenzaban a advertir, con razón, que había, en Regla, del otro lado de la bahía, ritmos tan complejos e interesantes
} 
en verde, es la "naturaleza vista en profundidad" (Carpentier, Tristán 31). La espectacularidad de la poética lamiana es asumida como patrón estético en el escrito liminar a El reino de este mundo, pues, para el autor, el modelo lamiano, a las antípodas del vanguardismo extremo de Dalí, Masson o Picasso, se resuelve en una síntesis de tradiciones de distinta procedencia. Esa condición oximorónica de la pintura de Lam interesa a Carpentier por su eficiencia en la asunción y recodificación de los postulados estéticos más recientes, por su negativa a comulgar a pies juntillas con los dogmas del arte nuevo y por la dramatización protagónica que la identidad americana adquiere en su obra: "André Masson quiso dibujar la selva de la isla Martinica con el increíble entrelazamiento de sus plantas y la obscena promiscuidad de ciertos frutos [...] Y tuvo que ser un pintor de América, Wifredo Lam, quien nos enseñara la magia de la vegetación tropical" (9).

Es desde este punto que pueden bosquejarse las filiaciones de Carpentier con la obra de Richard Wagner. El modelo wagneriano se inscribe en esa tendencia caníbal, porosa, que autores posteriores como Villa-Lobos o el Stravinski de La consagración de la primavera tomaron como matriz (si no en lo material, en la técnica), pues es un modelo que fagocita el sustrato popular (mitos, leyendas, etc.), lo asume y lo normativiza en el seno de otras grandes estructuras sinfónicas. Análogamente, en sus cuadros, Wifredo Lam opera en la misma dirección y toma del terruño sus fuentes. Carpentier lo reflexiona: "Wagner se valió de sus mitos, de su patrimonio cultural, como nosotros, tarde o temprano, tendremos que valernos de nuestros mitos y de nuestro ubérrimo patrimonio cultural" (Carpentier, Tristán 42).

El alcance utópico del proyecto wagneriano, espacio singular en el que se dirimen cuestiones identitarias complejas, se traduce en una noción de obra de arte como objeto total que implica el borrado de las fronteras entre géneros y códigos. Reciclaje, filtrado y refundición parecen ser, secuencialmente, los tres ciclos rectores de la poética wagneriana; una poética en la que música, ritmo, literatura, teatro, escultura y performance se imbrican para resolverse en una obra de arte total. El origen romántico del postulado es evidente. Valga el siguiente ejemplo: "la poesía romántica es una progresiva poesía universal. Su destino no es solo volver a reunir los géneros divididos de la poesía [...] Quiere y debe, ora mezclar, ora fundir la poesía y la prosa, la

como los que Stravinsky había creado para evocar los juegos primitivos de la Rusia pagana" (306). 
genialidad y la crítica, la poesía artística y la natural" (Schlegel 182). La desarticulación del espacio genérico interesa a Carpentier por su tendencia omnívora y por su voluntad expresa de ensanchar el horizonte de expectativas de sus coetáneos:

La obra de Ricardo Wagner fue síntesis de una cultura. Síntesis del romanticismo universal, síntesis de lo germánico. Por ello, al considerar nuevamente su obra, no debemos olvidar que nosotros también debemos propender a la síntesis [...] América habrá hallado su verdadera voz, cuando haya establecido verdaderas síntesis de sus herencias culturales y raciales y tenga una conciencia de la universalidad de sus mitos. Hay que realizar con lo latinoamericano algo semejante a lo que Wagner realizó con lo romántico y lo alemán (Carpentier, Tristán 42).

Estas ideas nucleares vertebran las distintas capas de escritura de Tristán e Isolda en Tierra Firme. El ensayo contiene algunas de la claves de lectura de la narrativa carpenteriana desde El reino de este mundo en adelante y, sin embargo, es un texto de difícil acceso que solo cuenta con una edición. El texto justifica esa cesura epocal que disocia el joven Carpentier -el de EcuéYamba-Ó- con el que, por lo común, ha sido objeto de estudio de la crítica y que se emplaza después de la publicación de sus ensayos musicales de mayor relieve: La música en Cuba (1946) y Tristán e Isolda en Tierra Firme (1949). La articulación de un itinerario homogéneo es una ficción crítica que pretendía refutar a lo largo de este escrito. No entiendo, con todo, esta secuencia en términos traumáticos o de ruptura, sino como discontinuidad, como viraje estético o transubstanciación ontológica de los materiales que el joven Carpentier recolectó en su aventura con el Grupo Minorista cubano, al amparo del magisterio del antropólogo Fernando Ortiz.

Este ensayo permite, en definitiva, establecer un sistema de relaciones que acaso resulte esclarecedor para cifrar genealógicamente el itinerario productivo del autor.

\section{LA PALABRA RECUPERADA}

La articulación del ensayo Tristán e Isolda en Tierra Firme fue un gesto de escritura poderoso. Supuso la delineación de un topos mesiánico desde el cual el autor asumió un rol como fundador y espíritu tutelar. Carpentier supo leer 
la necesidad de un cambio que rebasase el espíritu de la novela regionalista y el vanguardismo y, con su ensayo, validó la visión bolivariana de América como unidad. Pensaba en términos continentales al tratar de dotar a América Latina de un lenguaje renovado, de un manifiesto propio cimentado sobre un sustrato reconstituido de ideas románticas. El autor lo reflexiona:

Viejo ya, Víctor Hugo declaraba (en 1869) que el romanticismo había sido algo como la revolución francesa hecha literatura. En todo caso, una nueva Declaración de Derechos del Hombre [...] desde el Sturm und Drang, desde Freischütz, la Novena Sinfonía, el prefacio de Cromwell, el "caballero de Aquitania" de Nerval, los Caprichos de Goya, Tristán, Peleas y Melisenda, La Consagración de la Primavera, obras todas englobadas dentro de la misma órbita (Carpentier, Tristán 18; énfasis del autor).

En ese sentido, frente a otras autofiguraciones de autor de tipo más oscilatorio, y no por ello menos eficientes (ahí queden las autorrepresentaciones que Macedonio Fernández, Di Benedetto, Felisberto Hernández, Mario Bellatin o César Aira elaboraron de sí), Carpentier postula un proyecto de escritura duro, dogmático y transformador, en el que el escritor desempeñe un papel sociopolítico de relieve que se traduzca en la intervención tutelar de la realidad. Carpentier tiene en mente, todavía, la figura del intelectual decimonónico, el modelo balzaquiano, que cifra en la novela las virtudes de las ciencias positivas, capaces de establecer diagnósticos epistemológicamente válidos desde los que intervenir la realidad y modificar su curso. Esta autofiguración, mesiánica, será el anclaje desde el que el autor funde una poética que circula, primero, de modo fragmentario, a través de sus artículos periodísticos y el prólogo a El reino de este mundo, y, ya más tarde, cristalizada, en su narrativa de madurez y en su ensayística literaria de mayor calado: Razón de ser y Tientos y diferencias, entre otros textos nucleares.

Los autores del 'boom' no han dejado de atestiguar sus filiaciones con esa poética. El maravillosismo de Márquez en Cien años de soledad o El otoño del patriarca, la polifonía narratológica de La ciudad y los perros de Vargas Llosa, la escritura telúrica de Carlos Fuentes, o el realismo alucinado de El obsceno pájaro de la noche de José Donoso se deben, entre otros muchos estímulos, al influjo carpenteriano, reformulado y codificado en La música en Cuba y Tristán e Isolda en Tierra Firme. Es desde ese punto que considero, con las debidas precauciones, que Tristán e Isolda en Tierra Firme puede leerse como un manifiesto generacional, pues su influencia se 
resolvería, por vía indirecta (a través de otras realizaciones), en la prosa del 'boom'3 . El ensayo de Carpentier fue leído de soslayo, entre líneas, desde la prosa autoral o desde su articulismo, en una palabra que preexiste en Tristán e Isolda en Tierra Firme.

Quedó eso. Un legado alucinado, citado por vía indirecta, que todavía hoy seguimos leyendo y releyendo a través de las páginas de esos otros escritores. Así, Carpentier logró avanzar en el ambicioso proyecto de una novela panamericana con sus propios retoños en la década de los sesenta.

\section{BIBLIOGRAFÍA}

Baujín, José Antonio. "Carpentier: de las lecturas a los juicios críticos sobre la obra de Valle Inclán”. Temas 47 (2006): 82-92.

Carpentier, Alejo. Tristán e Isolda en Tierra Firme. Caracas: Imprenta Nacional de Caracas, 1949. Razón de ser. Caracas: Universidad Central de Caracas, 1976.

La novela latinoamericana en vísperas de un nuevo siglo y otros ensayos. Madrid: Siglo Veintiuno Editores, 1981.

Écue-Yamba-Ó, en Obras completas (vol. I). México: Siglo XXI Editores, 1983. La música en Cuba. México: Fondo de Cultura Económica, 2004.

El reino de este mundo. Madrid: Alianza Editorial, 2011.

Garí, Bernat. "La ensayística musicológica de Alejo. Eufónica vía a una poética de la novela". Tesis doctoral. Universitat de Barcelona, 2015.

"De unas desiguales nupcias entre doña Lira y don Bongó. Teoría de un arte mestizo a través del ensayo La música en Cuba de Alejo Carpentier". Cartaphilus: Revista de Investigación y Crítica Estética 13 (2015): 70-80.

"Sobre un novísimo concepto: la microcosmía sinfónica. Pesquisas identitarias desde el ensayismo musicológico de Carpentier". Tonos digital. Revista electrónica de estudios filológicos 31 (2016): s.p.

Guillén, Claudio. Entre lo uno y lo diverso. Introducción a la literatura comparada (ayer y hoy). Barcelona: Tusquets, 2005.

3 Con precaución, porque, como sabemos, el problemático membrete de "boom" es multifactorial y engloba narrativas de muy distinta índole con estímulos de distinta procedencia. Ahí queden los aportes de Borges, Bioy Casares, Felisberto Hernández, Miguel Ángel Asturias, etc. 
Leante, César. "Confesiones sencillas de un escritor barroco". Homenaje a Alejo Carpentier. Variaciones interpretativas en torno a su obra. Coord. Helmy F. Giacoman. New York: Las Americas Publishing, 1970. 11-31.

Ortega y Gasset, José. La deshumanización del arte. Madrid: Alianza Editorial, 2004.

Safranski, Rüdiger. Romanticismo. Una odisea del espíritu alemán. Barcelona: Tusquets, 2009. Schlegel, Friedrich. Kritische Ausgabe. Munich: Paderborn y Viena, 1967. 